\title{
Evaluation of university performance using BSC and ANP
}

\author{
Ali Atafar ${ }^{a^{*}}$, Mohsen Ameri Shahrabi ${ }^{\mathrm{b}}$ and Mohammad Javad Esfahani ${ }^{\mathrm{c}}$
}

${ }^{a}$ Department of Management, University of Isfahan, Isfahan, Iran

${ }^{b}$ Department of English and Management, Islamic Azad University, Naragh Branch, Naragh, Iran

${ }^{c}$ Department of Industrial Engineering, Islamic Azad University, Naragh Branch, Naragh, Iran

\section{H R O N I C L E}

\section{Article history:}

Received October 2, 2012

Accepted June 3, 2013

Available online

June 162013

Keywords:

Balanced Score Card

$B S C$

$A N P$

\section{A B S T R A C T}

Measuring the relative performance of universities play important role on better educational planning. During the past few years, balanced scorecard (BSC) has become popular among researchers as a technique for measuring the performance of business units. This method studies a particular firm in terms of four different perspectives including internal processes, learning and growth, customer and financial figures. One primary concern on using such method is that this method does not consider the relative importance of these components. In this paper, we present a hybrid of BSC with analytical network process to measure the relative performance of an educational unit in Iran.

(C) 2013 Growing Science Ltd. All rights reserved.

\section{Introduction}

The success of any educational organization depends on the quality of its management and management quality relies on decision quality and information quality on the quality of its measurement and proportion. Therefore, its precision and measurement plays essential role for the success of the firms and the weakness of performance evaluation and managerial control system can create some barriers for the growth of the firms. Performance evaluation systems can be categorized into two groups of traditional and modern group. The second group includes development and improvement of the capacity of based on organizational objectives and strategies. One of the most popular strategic models in this field is the balanced scorecard (BSC) model (Kaplan \& Norton, 1992, 1996a, 1996b, 2000, 2004). In this model, the entire aspects of an organization are investigated, dominantly. Mozaffari et al. (2012) presented an operational trend for the implementation of BSC model based on multiple criteria decision making (MCDM) techniques. They proposed a strategic planning for Islamic Azad university of Semnan and suggested a framework to validate the suggested structure's capacities.

* Corresponding author.

E-mail addresses: attafar@yahoo.com (A. Atafar)

(C) 2013 Growing Science Ltd. All rights reserved. doi: $10.5267 /$ j.ds1.2013.06.004 
According to Khosroabadi et al. (2012), one of the most popular techniques to increase the performance of educational services such as public or private universities is to make performance measurement. This could be accomplished using the people who work for these organizations since they are the best people to judge about the performance of a workplace and they know most existing weakness points in their workplace. Khosroabadi et al. (2012) looked into a university performance in three inside, process and outside's perspectives. They designed and distributed a questionnaire among 69 university professors and 295 students and asked them how they evaluated university in terms of different criteria such as educational and research facilities, etc. The results of their survey indicated that the university was not in good condition in terms of research activities but it had maintained good condition in terms of other perspectives such as educational, infrastructure, etc.

Shojaee et al. (2012) presented a study to setup appropriate strategies using the implementation of $\mathrm{BSC}$ in four perspectives of customers, processes, learning and financial. They gathered important factors through three various brainstorming sessions and prioritized them using TOPSIS method. Based on the results of MCDM technique, selecting appropriate target market for penetration was the number one priority followed by having good accounting system and preparing for more diversified production. Alvandi et al. (2012) provided some key performance indicators through literature reviews and experts' idea in SAPCO, which is one of the biggest vehicle spare suppliers in Iran. The proposed study uses decision making trial and evaluation laboratory (DEMATEL) and analytic network process (ANP) developed by Saaty (2004), respectively to measure the casual relationship between the perspectives as well as the relative weights. The results based on ANP method indicated that "Customer" was the most influential factor. In addition, internal process, financial and learning and growth were in two to four positions. The proposed model of this paper uses the similar approach used by Avandi et al (2012) to measure the relative performance of an educational unit.

\section{The proposed model}

The proposed model of this paper uses ANP and BSC and therefore, we briefly describe these two methods in this paper.

\subsection{BSC method}

BSC approach is a popular strategic planning system used in business and industry and it is actually a management system, which helps organizations clearly define their objectives and strategies (Olson \& Slater, 2002). Kaplan and Norton (1992) are believed to be the first who introduced the concept of BSC. The primary objective of BSC is to replace and to change the traditional performance evaluation model, which solely concentrated on financial indexes to obtain more complete and efficient evaluation of organizational performance.

1. Financial aspect: This perspective considers how organizations benefit from their strategic activities.

2. Customer aspect: This perspective concentrates on the issue that organizations should benefit of their inherent and available resources for the distinction among their competitors.

3. Internal business process aspect: All the strategic activities within an organization performed for satisfying stockholder and customer's expectations are considered in this part. General process is started by perception of customer's requirements and the operational and sale processes are executed after that.

4. Growth and learning aspect: When organizations plan to keep permanent activity and development, they should always depend on constant growth and innovation. According to Kaplan 
and Norton "organizations have to emphasize on some principals such as promotion of employee's capabilities and abilities, information system performance, persuasion and etc.".

\subsection{ANP method}

The BSC is an MCDM problem since it involves various criteria and there are literally various MCDM techniques for ranking various alternatives. However, many MCDM methods do not deal with the interdependences among elements and to handle such problem, the analytical network process (ANP) as a new MCDM method was proposed by Saaty (1996). Saaty (1999) has demonstrated different types of ANP models, such as the Hamburger Model, the Car Purchase BCR model, and the National Missile Defense model. However, from the viewpoint of Kinosita (2003), the ANP can be differentiated into two practical types of techniques: the Feedback System model and the Series System model. According to the Feedback System model, clusters link one by one in turn as a network system. This type of model can capture effectively the complex impacts of interplay in human society, especially when risk and uncertainty are involved (Saaty, 2004). However, it is usually difficult to obviate the possibility of interactions within the criteria cluster. Therefore, the proposed model of this paper suggests a modified Feedback System model (Fig. 1) that allows inner dependences within the criteria cluster, in which the looped are signifies the inner dependences.

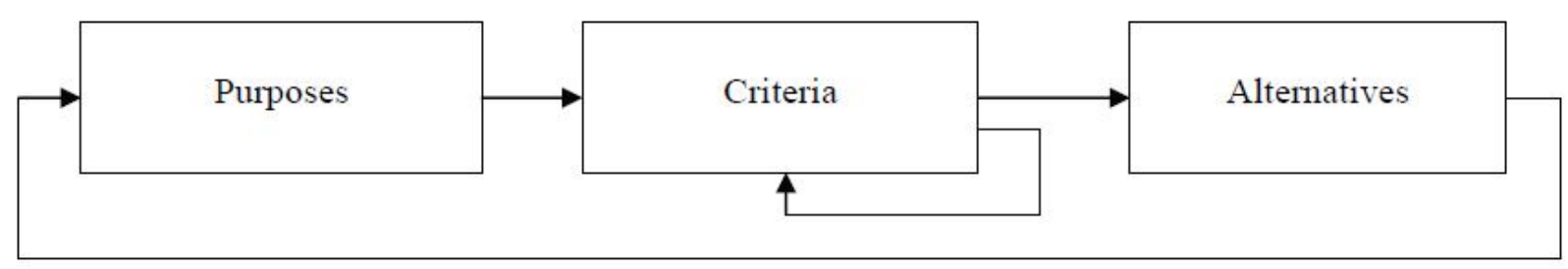

Fig.1. Feedback system model

To determine the relative importance among elements, decision makers are requested to respond through a series of pair-wise comparisons. These pair-wise comparisons are based on the Saaty's nine-point scale ranging from 1 (equal) to 9 (extreme). For evaluating the weights of elements, the AHP uses the principal eigenvector of comparison matrix, whereas the ANP employs the limiting process method of the powers of the super-matrix (Sekitani \& Takahashi, 2001).

\section{The case study}

As we explained earlier, the proposed study of this paper has been implemented in one of Islamic Azad Universities in Iran. Fig. 2 demonstrates details of criteria used for this study. As we can observe from the this figure, the BSC structure consists of four perspectives of financial $\left(\mathrm{C}_{1}\right)$, customer $\left(\mathrm{C}_{2}\right)$, process $\left(\mathrm{C}_{3}\right)$ and learning and growth $\left(\mathrm{C}_{4}\right)$. The first perspective, financial, includes four sub-criteria including sufficient financial infrastructure, increase in income, increase in return on assets (ROA) and reduction on employee expenses. The second perspective, customer, includes three perspectives including increase in customer satisfaction, perception improvement and consistent with customer's expectations. The third item, process, incorporates four sub-criteria including consistency in service delivery process, completion in training facilities, quality improvement and information technology development. Finally, the last perspective, learning and growth, consists of four elements, which are order and coherence, giving research assistance, increase the competence and ability of staff and increase in research paper publications. The next step is to prepare $W_{i j}$ with $i=2,3$ and $j=1,2,3$ associated with the implementation of ANP. In order to do this part, we ask decision maker to make judgment about the relative importance of on alternative versus another one and possible interdependencies. 


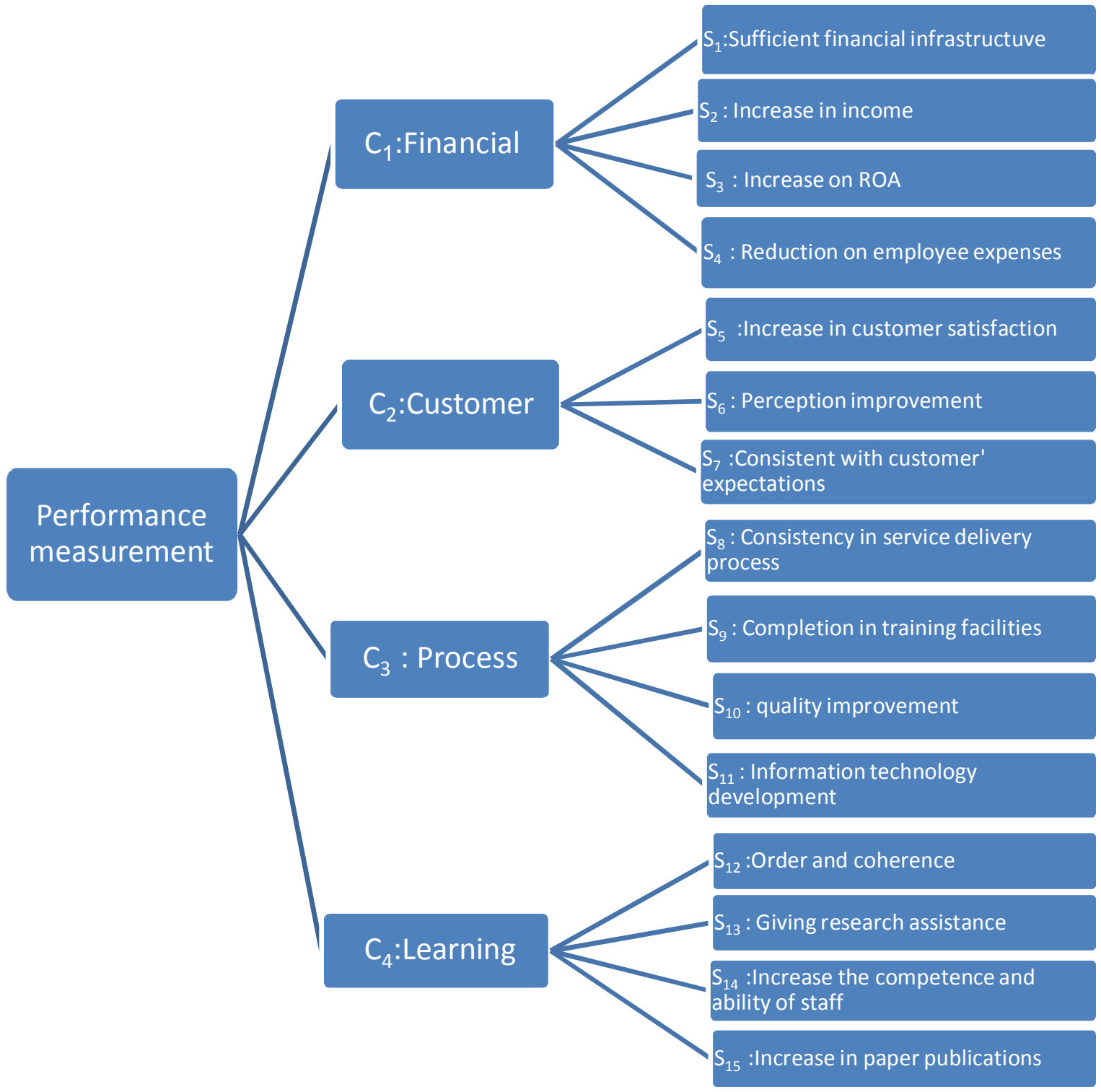

Table 1

Fig. 2. The proposed framework of the study

The summary of $\mathrm{W}_{23}$ matrix and $\mathrm{W}_{21}$ vector

\begin{tabular}{|c|c|c|c|c|c|c|}
\hline \multirow{2}{*}{\multicolumn{2}{|c|}{$\left(\mathrm{W}_{21}\right)$}} & & \multicolumn{3}{|c|}{$\left(\mathrm{W}_{32}\right)$} & \multirow[b]{2}{*}{$\mathrm{C}_{4}$} \\
\hline & & & $\mathrm{C}_{1}$ & $\mathrm{C}_{2}$ & $\mathrm{C}_{3}$ & \\
\hline \multirow{4}{*}{$\mathrm{C}_{1}$} & \multirow{4}{*}{0.279} & $\mathrm{~S}_{1}$ & 0.239 & 0 & 0 & 0 \\
\hline & & $\mathrm{S}_{2}$ & 0.295 & 0 & 0 & 0 \\
\hline & & $\mathrm{S}_{3}$ & 0.243 & 0 & 0 & 0 \\
\hline & & $\mathrm{S}_{4}$ & 0.223 & 0 & 0 & 0 \\
\hline \multirow{3}{*}{$\mathrm{C}_{2}$} & \multirow{3}{*}{0.262} & $\mathrm{~S}_{5}$ & 0 & 0.436 & 0 & 0 \\
\hline & & $\mathrm{S}_{6}$ & 0 & 0.298 & 0 & 0 \\
\hline & & $\mathrm{S}_{7}$ & 0 & 0.266 & 0 & 0 \\
\hline \multirow{4}{*}{$\mathrm{C}_{3}$} & \multirow{4}{*}{0.243} & $\mathrm{~S}_{8}$ & 0 & 0 & 0.224 & 0 \\
\hline & & $\mathrm{S}_{9}$ & 0 & 0 & 0.235 & 0 \\
\hline & & $\mathrm{S}_{10}$ & 0 & 0 & 0.303 & 0 \\
\hline & & $\mathrm{S}_{11}$ & 0 & 0 & 0.238 & 0 \\
\hline \multirow{4}{*}{$\mathrm{C}_{4}$} & \multirow{4}{*}{0.216} & $\mathrm{~S}_{12}$ & 0 & 0 & 0 & 0.241 \\
\hline & & $\mathrm{S}_{13}$ & 0 & 0 & 0 & 0.227 \\
\hline & & $\mathrm{S}_{14}$ & 0 & 0 & 0 & 0.262 \\
\hline & & $\mathrm{S}_{15}$ & 0 & 0 & 0 & 0.270 \\
\hline
\end{tabular}


Table 2

Internal relationship between four BSC perspectives

\begin{tabular}{lcccc}
\hline Criteria & Financial $\left(\mathrm{C}_{1}\right)$ & Customer $\left(\mathrm{C}_{2}\right)$ & Process $\left(\mathrm{C}_{3}\right)$ & Learning and growth $\left(\mathrm{C}_{4}\right)$ \\
\hline Financial $\left(\mathrm{C}_{1}\right)$ & $\sqrt{ }$ & $\sqrt{ }$ & $\sqrt{ }$ \\
Customer $\left(\mathrm{C}_{2}\right)$ & $\sqrt{ }$ & $\sqrt{ }$ & $\sqrt{ }$ \\
Process $\left(\mathrm{C}_{3}\right)$ & $\sqrt{ }$ & $\sqrt{ }$ & $\sqrt{ }$ & \\
Learning and growth $\left(\mathrm{C}_{4}\right)$ & $\sqrt{ }$ & $\sqrt{ }$ & \\
\hline
\end{tabular}

\section{Table 3}

Internal relationship between sub-criteria associated with four main BSC perspectives

\begin{tabular}{|c|c|c|c|c|c|c|c|c|c|c|c|c|c|c|c|}
\hline & $\mathrm{S}_{1}$ & $\mathrm{~S}_{2}$ & $\mathrm{~S}_{3}$ & $\mathrm{~S}_{4}$ & $\mathrm{~S}_{5}$ & $\mathrm{~S}_{6}$ & $\mathrm{~S}_{7}$ & $\mathrm{~S}_{8}$ & $\mathrm{~S}_{9}$ & $\mathrm{~S}_{10}$ & $\mathrm{~S}_{11}$ & $\mathrm{~S}_{12}$ & $\mathrm{~S}_{13}$ & $\mathrm{~S}_{14}$ & $\mathrm{~S}_{15}$ \\
\hline $\mathrm{S}_{1}$ & & & $\sqrt{ }$ & $\sqrt{ }$ & $\sqrt{ }$ & & $\sqrt{ }$ & & $\sqrt{ }$ & $\sqrt{ }$ & & $\sqrt{ }$ & $\sqrt{ }$ & & $\sqrt{ }$ \\
\hline $\mathrm{S}_{2}$ & & & $\sqrt{ }$ & & $\sqrt{ }$ & & $\sqrt{ }$ & $\sqrt{ }$ & & $\sqrt{ }$ & $\sqrt{ }$ & & $\sqrt{ }$ & & $\sqrt{ }$ \\
\hline $\mathrm{S}_{3}$ & $\sqrt{ }$ & $\sqrt{ }$ & 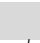 & $\sqrt{ }$ & & $\sqrt{ }$ & 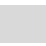 & $\sqrt{ }$ & $\sqrt{ }$ & & $\sqrt{ }$ & & $\sqrt{ }$ & $\sqrt{ }$ & \\
\hline $\mathrm{S}_{4}$ & $\sqrt{ }$ & & $\sqrt{ }$ & & $\sqrt{ }$ & $\sqrt{ }$ & & $\sqrt{ }$ & & & $\sqrt{ }$ & $\sqrt{ }$ & & & $\sqrt{ }$ \\
\hline $\mathrm{S}_{5}$ & $\sqrt{ }$ & $\sqrt{ }$ & 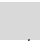 & $\sqrt{ }$ & & & $\sqrt{ }$ & 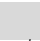 & $\sqrt{ }$ & & & $\sqrt{ }$ & & $\sqrt{ }$ & \\
\hline $\mathrm{S}_{6}$ & & & $\sqrt{ }$ & $\sqrt{ }$ & & & $\sqrt{ }$ & $\sqrt{ }$ & & $\sqrt{ }$ & & $\sqrt{ }$ & & & $\sqrt{ }$ \\
\hline $\mathrm{S}_{7}$ & $\sqrt{ }$ & $\sqrt{ }$ & . & 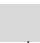 & $\sqrt{ }$ & $\sqrt{ }$ & & . & - & 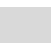 & $\sqrt{ }$ & & $\sqrt{ }$ & $\sqrt{ }$ & 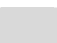 \\
\hline $\mathrm{S}_{8}$ & & $\sqrt{ }$ & $\sqrt{ }$ & $\sqrt{ }$ & & $\sqrt{ }$ & & & $\sqrt{ }$ & $\sqrt{ }$ & & $\sqrt{ }$ & $\sqrt{ }$ & & \\
\hline $\mathrm{S}_{9}$ & $\sqrt{ }$ & 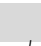 & $\sqrt{ }$ & - & $\sqrt{ }$ & & & $\sqrt{ }$ & & $\sqrt{ }$ & $\sqrt{ }$ & $\sqrt{ }$ & & $\sqrt{ }$ & \\
\hline $\mathrm{S}_{10}$ & $\sqrt{ }$ & $\sqrt{ }$ & & & & $\sqrt{ }$ & & $\sqrt{ }$ & $\sqrt{ }$ & & $\sqrt{ }$ & $\sqrt{ }$ & & $\sqrt{ }$ & $\sqrt{ }$ \\
\hline $\mathrm{S}_{11}$ & & $\sqrt{ }$ & $\sqrt{ }$ & $\sqrt{ }$ & & & $\sqrt{ }$ & & $\sqrt{ }$ & $\sqrt{ }$ & & & $\sqrt{ }$ & $\sqrt{ }$ & $\sqrt{ }$ \\
\hline $\mathrm{S}_{12}$ & $\sqrt{ }$ & & & $\sqrt{ }$ & $\sqrt{ }$ & $\sqrt{ }$ & & $\sqrt{ }$ & $\sqrt{ }$ & $\sqrt{ }$ & & & & $\sqrt{ }$ & $\sqrt{ }$ \\
\hline $\mathrm{S}_{13}$ & $\sqrt{ }$ & $\sqrt{ }$ & $\sqrt{ }$ & & & & $\sqrt{ }$ & $\sqrt{ }$ & & & $\sqrt{ }$ & & & $\sqrt{ }$ & $\sqrt{ }$ \\
\hline $\mathrm{S}_{14}$ & & & $\sqrt{ }$ & & $\sqrt{ }$ & & $\sqrt{ }$ & & $\sqrt{ }$ & $\sqrt{ }$ & $\sqrt{ }$ & $\sqrt{ }$ & $\sqrt{ }$ & & $\sqrt{ }$ \\
\hline $\mathrm{S}_{15}$ & $\sqrt{ }$ & $\sqrt{ }$ & & $\sqrt{ }$ & & $\sqrt{ }$ & & & & $\sqrt{ }$ & $\sqrt{ }$ & $\sqrt{ }$ & $\sqrt{ }$ & $\sqrt{ }$ & \\
\hline
\end{tabular}

The relative weight for the main criteria are calculated and summarized in Table 4 as follows,

\section{Table 4}

The summary of relative weights for different criteria

\begin{tabular}{lcccc}
\hline Criteria & Financial $\left(\mathrm{C}_{1}\right)$ & Customer $\left(\mathrm{C}_{2}\right)$ & Process $\left(\mathrm{C}_{3}\right)$ & Learning and growth $\left(\mathrm{C}_{4}\right)$ \\
\hline Financial $\left(\mathrm{C}_{1}\right)$ & & 0.423 & 0.303 & 0.279 \\
Customer $\left(\mathrm{C}_{2}\right)$ & 0.428 & & 0.345 & 0.429 \\
Process $\left(\mathrm{C}_{3}\right)$ & 0.275 & 0.285 & & 0.292 \\
Learning and growth $\left(\mathrm{C}_{4}\right)$ & 0.297 & 0.292 & 0.352 & \\
\hline
\end{tabular}

Similarly, we have computed the relative weights of all sub-criteria and the results are summarized in Table 5 as follows,

Table 5

The summary of relative weights for sub-criteria

\begin{tabular}{|c|c|c|c|c|c|c|c|c|c|c|c|c|c|c|c|}
\hline & $\mathrm{S}_{1}$ & $\mathrm{~S}_{2}$ & $\mathrm{~S}_{3}$ & $\mathrm{~S}_{4}$ & $\mathrm{~S}_{5}$ & $S_{6}$ & $S_{7}$ & $\mathrm{~S}_{8}$ & $\mathrm{~S}_{9}$ & $\mathrm{~S}_{10}$ & $\mathrm{~S}_{11}$ & $\mathrm{~S}_{12}$ & $\mathrm{~S}_{13}$ & $\mathrm{~S}_{14}$ & $\mathrm{~S}_{15}$ \\
\hline $\mathrm{S}_{1}$ & & & 0.106 & 0.126 & 0.145 & & 0.134 & & 0.124 & 0.116 & & 0.097 & 0.131 & & 0.123 \\
\hline $\mathrm{S}_{2}$ & & & 0.114 & & 0.153 & & 0.144 & 0.141 & & 0.109 & 0.115 & & 0.128 & & 0.101 \\
\hline $\mathrm{S}_{3}$ & 0.125 & 0.135 & & 0.146 & & 0.159 & & 0.139 & 0.128 & & 0.106 & & 0.132 & 0.123 & \\
\hline $\mathrm{S}_{4}$ & 0.103 & & 0.121 & & 0.157 & 0.12 & & 0.134 & & & 0.123 & 0.113 & & & 0.095 \\
\hline $\mathrm{S}_{5}$ & 0.121 & 0.101 & & 0.13 & & & 0.133 & & 0.112 & & & 0.115 & & 0.089 & \\
\hline $\mathrm{S}_{6}$ & & & 0.124 & 0.148 & & & 0.139 & 0.101 & & 0.122 & & 0.124 & & & 0.116 \\
\hline $\mathrm{S}_{7}$ & 0.136 & 0.115 & & & 0.161 & 0.153 & & & & & 0.125 & & 0.102 & 0.102 & \\
\hline $\mathrm{S}_{8}$ & & 0.128 & 0.103 & 0.144 & & 0.148 & & & 0.131 & 0.116 & & 0.111 & 0.128 & & \\
\hline $\mathrm{S}_{9}$ & 0.119 & & 0.117 & & 0.122 & & & 0.107 & & 0.102 & 0.102 & 0.105 & & 0.112 & \\
\hline$S_{10}$ & 0.095 & 0.143 & & & & 0.145 & & 0.112 & 0.118 & & 0.103 & 0.112 & & 0.122 & 0.132 \\
\hline$S_{11}$ & & 0.099 & 0.1 & 0.096 & & & 0.151 & & 0.129 & 0.14 & & & 0.111 & 0.11 & 0.105 \\
\hline $\mathrm{S}_{12}$ & 0.085 & & & 0.1 & 0.136 & 0.139 & & 0.118 & 0.123 & 0.099 & & & & 0.126 & 0.099 \\
\hline $\mathrm{S}_{13}$ & 0.105 & 0.134 & 0.103 & & & & 0.158 & 0.148 & & & 0.098 & & & 0.109 & 0.104 \\
\hline$S_{14}$ & & & 0.112 & & 0.126 & & 0.141 & & 0.135 & 0.104 & 0.12 & 0.114 & 0.132 & & 0.125 \\
\hline $\mathrm{S}_{15}$ & 0.111 & 0.145 & & 0.11 & & 0.136 & & & & 0.092 & 0.108 & 0.109 & 0.136 & 0.107 & \\
\hline
\end{tabular}

Now we can form the super matrix of the following form, 
Goal
subcariteria
Alternetive $\left[\begin{array}{cccc}I & \cdot & \cdots & \cdot \\ W_{2} & W_{2} & \cdots & \cdot \\ \vdots & W_{3} & W_{3} & \vdots \\ \cdot & \cdot & W_{4} & I\end{array}\right]$

and provide the final ranking based on ANP process. Table 6 shows details of the results of the restricted super matrix associated with four alternatives.

Table 6

The summary of restricted super matrix associated with four alternatives

\begin{tabular}{|c|c|c|c|c|c|c|c|c|c|c|c|c|c|c|c|c|c|c|c|c|}
\hline & G & $C_{1}$ & $C_{2}$ & $C_{3}$ & $\mathrm{C}_{4}$ & $\mathrm{~S}_{1}$ & $\mathrm{~S}_{2}$ & $\mathrm{~S}_{3}$ & $\mathrm{~S}_{4}$ & $S_{5}$ & $\mathrm{~S}_{6}$ & $\mathrm{~S}_{7}$ & $\mathrm{~S}_{8}$ & $\mathrm{~S}_{9}$ & $\mathrm{~S}_{10}$ & $S_{11}$ & $\mathrm{~S}_{12}$ & $\mathrm{~S}_{13}$ & $\mathrm{~S}_{14}$ & $\mathrm{~S}_{15}$ \\
\hline$A_{1}$ & 0.27 & 0.27 & 0.27 & 0.26 & 0.27 & 0.27 & 00.3 & 0.37 & 0.29 & 0.23 & 0.26 & 0.28 & 0.25 & 0.28 & 0.22 & 0.29 & 0.21 & 0.27 & 0.35 & 0.31 \\
\hline$A_{2}$ & 0.32 & 0.31 & 0.32 & 0.32 & 0.31 & 0.3 & 0.19 & 0.13 & 0.32 & 0.32 & 0.30 & 0.29 & 0.24 & 0.24 & 0.32 & 0.21 & 0.19 & 0.33 & 0.24 & 0.28 \\
\hline$A_{3}$ & 0.20 & 0.20 & 0.20 & 0.19 & 0.21 & 0.22 & 0.35 & 0.21 & 0.28 & 0.26 & 0.22 & 0.26 & 0.21 & 0.22 & 0.25 & 0.29 & 0.26 & 0.21 & 0.26 & 0.23 \\
\hline $\mathrm{A}_{4}$ & 0.21 & 0.21 & 0.22 & 0.21 & 0.21 & 0.19 & 0.15 & 0.3 & 0.11 & 0.19 & 0.23 & 0.17 & 0.30 & 0.26 & 0.21 & 0.21 & 0.34 & 0.19 & 0.15 & 0.18 \\
\hline
\end{tabular}

As we can observe from the results of Table 6 , the second alternative $\left(A_{2}\right)$ has received the highest priority, 0.32, followed by the first alternative $\left(\mathrm{A}_{1}\right), 0.27$, the fourth $\left(\mathrm{A}_{4}\right), 0.21$ and the third one, $\left(\mathrm{A}_{3}\right)$ with the relative weight of 0.20 . In addition, we have computed the relative weights of all criteria and they are summarized in Table 7 as follows,

Table 7

The summary of weights associated with different criteria

\begin{tabular}{ccllllrc}
\hline \multicolumn{2}{l}{ Financial(0.265) } & \multicolumn{2}{l}{ Customer(0.375) } & \multicolumn{2}{c}{ Process $(0.145)$} & \multicolumn{2}{c}{ Learning and growth $(0.215)$} \\
\hline $\mathrm{S}_{1}$ & 0.012 & $\mathrm{~S}_{5}$ & 0.185 & $\mathrm{~S}_{8}$ & 0.054 & $\mathrm{~S}_{12}$ & 0.018 \\
$\mathrm{~S}_{2}$ & 0.203 & & & $\mathrm{~S}_{9}$ & 0.003 & $\mathrm{~S}_{13}$ & 0.055 \\
$\mathrm{~S}_{3}$ & 0.014 & $\mathrm{~S}_{6}$ & 0.035 & $\mathrm{~S}_{10}$ & 0.111 & $\mathrm{~S}_{14}$ & 0.023 \\
$\mathrm{~S}_{4}$ & 0.085 & $\mathrm{~S}_{7}$ & 0.068 & $\mathrm{~S}_{11}$ & 0.009 & $\mathrm{~S}_{15}$ & 0.125 \\
\hline
\end{tabular}

According to the results of Table 7, customer plays the most important role followed by financial, learning and growth and process.

\section{Conclusion}

In this paper, we have presented a multiple criteria decision making method for strategic planning of some Islamic Azad University branches. The proposed study of this paper has implemented balance scorecard along with analytical hierarchy process to investigate the university in terms of four different perspectives. We have also used analytical hierarchy process to rank various components of each perspective. Based on the results of this survey, we can conclude that customer has been the most important component of this university followed by financial, learning and growth and process.

\section{References}

Alvandi, M., Fazli, S., Yazdani, L \& Aghaee, M. (2012). An integrated MCDM method in ranking BSC perspectives and key performance indicators (KPIs). Management Science Letters, 2(3), 9951004.

Kaplan, R. S., \& Norton, D. (1992). The balanced scorecard measures that drive performance. Harvard Business Review, 70(1), 71-79.

Kaplan, R.S., \& Norton, D. (1996a). Using the balanced scorecard as a strategic management system. Harvard Business Review, 74(1), 75-85.

Kaplan, R.S., \& Norton, D.P. (1996b). The Balanced Scorecard: Translating Strategy into Action. Harvard Business School Press.

Kaplan, R.S., \& Norton, D.P. (2000). The strategy-focused organization: How balanced scorecard companies thrive in the new business environment. Harvard Business Press. 
Kaplan, R.S., \& Norton, D.P. (2004). Strategy maps: Converting intangible assets into tangible outcomes. Boston, MD: Harvard Business Press.

Khosroabadi, S., Monfaredi raz, B., \& Bahramzadeh, H. (2012). A survey for assessing university performance. Management Science Letters, 2(8), 3061-3066.

Kinosita. E. (2003). From AHP to ANP. Operations Research of Japan, 48(9), 677-683.

Mozaffari, A., Karkehabadi, H., Kheyrkhahan, M \& Karami, M. (2012). A development in balanced scorecard by designing a fuzzy and nonlinear Algorithm (case study: Islamic Azad university of Semnan). Management Science Letters, 2(5), 1819-1838.

Olson, E.M., \& Slater, S.F. (2002). The balanced scorecard, competitive strategy, and performance. Business Horizons, 45, 11-16.

Saaty, T. L. (1996). The analytic network process-decision making with dependence and feedback. Pittsburgh, PA: RWS Publications.

Saaty, T. L. (2004). Decision making - the analytic hierarchy and network processes (AHP/ANP). Journal of systems science and systems engineering, 13(1), 1-35.

Sekitani, K., \& Takahashi, I. (2001). A unified model and analysis for AHP and ANP. Journal of the Operations Research Society of Japan, 44(1), 67-89.

Shojaee, M., Fallah, M \& Fallah, M. (2012). A hybrid TOPSIS-BSC method for strategic planning. Management Science Letters, 2(8), 2845-2850. 